\title{
HUBUNGAN POLA ASUH ORANG TUA DENGAN PERILAKU JAJAN ANAK USIA SEKOLAH (9-12 TAHUN) DI SD GMIM SENDANGAN SONDER
}

\author{
Jesica S. Lonto \\ Adrian Umboh \\ Abram Babakal \\ Program Studi Ilmu Keperawatan Fakultas Kedokteran \\ Universitas Sam Ratulangi \\ Email : jesicalonto5@gmail.com
}

\begin{abstract}
Parenting is a pattern of interaction between parents and children. Children and snack foods are two things that are difficult to resolve because children have a penchant for more food, especially children of primary school age. The Purpose of this study is to find out the relationship between parenting and school children's snacking behavior aged 9-12 years at SD GMIM Sendangan. The Method of this study uses cross-sectional study design, using the chi-square test, with total sampel taken amounted to 64 people. The Conclusions based on the results of the analysis using the Chi-Square test show that there is the relationship of Parenting with Snacking behavior in Children's schools aged 9-12 years at SD GMIM Sendangan Sonder with a significant value $=0.007$ less than $\alpha 0.05$.
\end{abstract}

Keywords : Parenting, Snacking Behavior

\begin{abstract}
Abstrak : Pola asuh orang tua merupakan pola interakasi antara orang tua dan anak. Anakanak dan makanan jajanan merupakan dua hal yang sulit untuk dipisahkan karena anak-anak memiliki kegemaran untuk mengkonsumsi jenis makanan secara berlebihan, khususnya anakanak usia sekolah dasar. Tujuan Penelitian : Untuk mengetahui Hubungan pola asuh orang tua dengan perilaku jajan anak sekolah Usia 9-12 Tahun di SD GMIM Sendangan. Desain Penelitian ini menggunakan penelitian cross sectional, dengan menggunakan uji chi-square dan teknik total sampling dengan jumlah sampel sebanyak 64 orang. Kesimpulan berdasarkan hasil analisis dengan menggunakan uji statistik chi-Square menunjukan terdapat hubungan Pola Asuh Orang Tua dengan Perilaku Jajan di sekolah Usia 9-12 Tahun di SD Gmim Sendangan Sonder dengan nilai signifikan $=0.007$ atau kurang dari $\alpha 0.05$.
\end{abstract}

Kata Kunci : pola asuh orang tua, perilaku jajan

\section{PENDAHULUAN}

Anak sekolah menurut definisi WHO (World Health Organization) yaitu golongan anak yang berusia antara 7-15 tahun, sedangkan di Indonesia lazimnya anak yang berusia 7-12 tahun. Menurut Gunarsa (2008), masa anak usia sekolah adalah masa tenang atau masa latent dimana apa yang telah terjadi dan dipupuk pada masa-masa sebelumnya akan berlangsung terus untuk masa-masa selanjutnya. Tahap usia ini disebut juga sebagai usia kelompok dimana anak mulai mengalihkan perhatian dan hubungan intim dalam keluarga kerjasama antar teman dan sikap-sikap terhadap kerja atau belajar. Anak sekolah biasanya memiliki masalah dalam memilih makanan, anak sekolah cenderung menyukai makanan yang dijual disekolah dari pada bekal yang dibawakan orang tua mereka. Anak-anak dan makanan jajanan merupakan dua hal yang sulit untuk dipisahkan karena anakanak memiliki kegemaran untuk mengkonsumsi jenis makanan secara berlebihan, khususnya anak-anak usia sekolah dasar (10-12 tahun). Banyak dijumpai dalam keseharian anak yang selalu dikelilingi penjual makanan jajanan, baik yang ada dirumah, dilingkungan 
tempat tinggal, hingga disekolah. Makanan jajanan tersedia dan disajikan dalam kemasan plastik, maupun makanan cepat saji fast food. (Sitoresmi, 2014).

Makanan jajanan adalah makanan dan minuman yang dipersiapkan dan dijual oleh pedagang kaki lima di jalanan dan di tempat-tempat keramaian umum lain yang langsung dimakan atau dikonsumsi tanpa pengolahan atau persiapan lebih lanjut. Ini mencakup buahbuahan segar dan sayuran yang dijual di luar wewenang daerah pasar untuk konsumsi langsung (WHO, 2013). Saat ini jajanan sekolah semakin beraneka ragam dari mulai jajanan tradisional sampai jajanan modern sehingga mampu menarik para siswa untuk mengkonsumsi jajanan sekolah. Ketersediaan jajanan sehat dan tidak sehat di sekolah berpengaruh terhadap pemilihan makanan jajanan pada anak-anak. Anak akan lebih cenderung untuk membeli makanan jajanan yang tersedia paling dekat dengan keberadaannya. Oleh sebab itu, jajanan yang sehat seharusnya tersedia baik di rumah, maupun di lingkungan sekolah agar akses anak terhadap jajanan sehat tetap terjamin (BPOM, 2010). Makanan jajanan berdampak negatif apabila makanan yang dikonsumsi tidak mengandung nilai gizi yang cukup dan tidak terjamin kebersihan serta keamanannya. Selain menimbulkan masalah gizi, dampak mengkonsumsi jajanan yang tidak baik akan mengganggu kesehatan anak seperti terserang penyakit saluran pencernaan dan dapat timbul penyakit-penyakit lainnya yang diakibatkan pencemaran bahan kimiawi. Sehingga hal ini berdampak pada menurunnya konsentrasi belajar siswa, meningkatnya absensi dapat berpengaruh pada prestasi belajar anak (Safriana, 2012).

Temuan Badan Pengawas Obat dan Makanan (BPOM) tahun 2014 mengenai presentase penyebab Pangan Jajanan Anak Sekolah (PJAS) yang tidak memenuhi syarat menunjukkan sebanyak $15,7 \%$ menggunakan Bahan Tambahan Pangan berlebihan, 74,9\% terjadi Pencemaran Mikroba dan 9\% mengandung Bahan Berbahaya. Pada tahun 2014 terdapat 7 jenis pangan yang diuji pada pengawasan PJAS, yang terdiri dari bakso (sebelum diseduh/disajikan), jelly/agar-agar/produk gelatin lainnya, minuman es (es mambo, lolipop, es lilin, es cendol, es campur, dan sejenisnya), mie (disajikan/siap dikonsumsi), minuman berwarna dan sirup, kudapan (makanan gorengan seperti bakwan, tahu goreng, cilok, sosis, batagor, empek-empek, lontong, dan lain-lain), makanan ringan (kerupuk, keripik, produk ekstrusi dan sejenisnya). Berdasarkan pemeriksaan sampel pangan yang paling tidak memenuhi syarat secara berturutturut adalah minuman berwarna/sirup, minuman es, jelly/agar-agar, dan bakso. Penyebab sampel tidak memenuhi syarat antara lain karena menggunakan bahan berbahaya yang dilarang untuk pangan, menggunakan bahan tambahan pangan melebihi batas maksimal, mengandung cemaran logam berat melebihi batas maksimal, dan kualitas mutu mikrobiologis yang tidak memenuhi syarat.

Perilaku jajan anak dipengaruhi oleh faktor lingkungan karena anak belum bisa membedakan jajanan yang baik dan tidak baik. Faktor lingkungan yang sangat berpengaruh dalam perilaku jajan anak adalah peran orang tua (Sitoresmi, 2014).Kemampuan orang tua untuk mengambil keputusan berdampak luas terhadap kehidupan seluruh anggota keluarga dan menjadi dasar pola pengasuhan yang tepat, termasuk penentuan asupan nutrisi. Pola asuh pemberian makan didefinisikan sebagai perilaku pengasuhan yang meliputi pemberian asupan nutrisi, pemberian makanan tambahan, serta pemberian dukungan emosional yang baik(Oemar \& Novita, 2015). Menurut Singgih D. Gunarso (2004), pola asuh orang tua merupakan perlakuan orang tua dalam interaksi yang meliputi orang tua menunjukkan kekuasaan dan cara orang 
tua memperhatikan keinginan anak cenderung mengarah pada pola asuh yang diterapkan. Selama ini banyak orang tua menganggap jika anaknya kelihatan sehat dan tetap bisa beraktifitas seperti biasa, maka orang tua beranggapan bahwa anaknya baik-baik saja. Karena orang tua mengetahui bahwa anaknya sudah terbebas dari rasa lapar, tetapi sebenarnya bahwa kecukupan gizi untuk kesehatan anak masih kurang bahkan menambah timbunan penyakit yang ditimbulkan dari makanan jajanan tersebut.

Studi pendahuluan yang di dapatkan di SD GMIM Sendangan Sonder tercatat memiliki jumlah siswa keseluruhan sebanyak 81 murid. Dari wawancara singkat yang dilakukan peneliti kepada 8 orang murid,didapat data bahwa 6 orang murid sering jajan makanan disekitar lingkungan sekolah misalnya essirup, cilok, dan minuman berwarna ( es loli, es goring dan lain-lain) sedangkan 2 murid yang lain jarang memakan jajanan karena biasa membawa bekal dari rumah. Berdasarkan latar belakang di atas, penulis tertarik untuk meneliti mengenai hubungan pola asuh orang tua dengan perilaku jajan anak usia sekolah di SD GMIM Sendangan Sonder.

\section{METODE PENELITIAN}

Penelitian kuantitatif dengan menganalisis gambaran hubungan antara kedua variabel yaitu variabel independen (Pola asuh orang tua) dan variabel dependen (Perilaku seksual anak usia sekolah (9-12). Penelitian ini menggunakan desain penelitian cross sectional. Penelitian ini dilaksanakan di SD GMIM Sendangan Sonder pada bulan maret 2019. Populasi penelitian ini seluruh kelas III-VI yang berjumlah 64 orang. Pengambilan sampel menggunakan teknik Sampel Jenuh maka didapatkan jumlah sampel yang memenuhi kriteria inklusi 64 sampel.

Instrumen penelitian yang digunakan untuk mengukur variabel pola asuh orang tua menggunakan kuesioner yang digunakan sebelumnya oleh Devi (2012) yang telah diuji validitasnya. Kuisioner yang digunakan dalam penelitian tentang pola asuh orangtua terdiri dari 25 pertanyaan. 9 pertanyaan untuk pola asuh Permisif, 9 pertanyaan untuk pola asuh otoriter dan 9 pertanyaan untuk pola asuh Demokrasi. Dengan kriteria skor dan pilihan $1=$ sangat tidak sesuai, 2=tidak sesuai, $3=$ sesuai, $4=$ sangat sesuai. permisif : skor tertinggi pada nomor pernyataan 1-9, demokratis : skor teringgi pada nomor pernyataan 10-18, otoriter: skor tertinggi pada nomor pernyataan 19-27. Setelah lembar kuesioner diisi oleh responden, kemudian dilakukan penghitungan skor dengan cara menjumlahkan skor tiap pertanyaan. Untuk menentukan jenis pola asuh yang diterapkan oleh orang tua dihitung dari jumlah skor tertinggi pada 3 jenis pola asuh tersebut.

Kuesioner untuk menilai perilaku jajan anak usia sekolah yang pernah digunakan sebelumnya oleh Mukhammad (2016), menggunakan skala guttman dengan jumlah 25 pertanyaan, di mana untuk jawaban Ya di beri skor 1 danjawaban tidak diberi skor 0. Kemudian dilakukan perhitungan dengan menggunakan Cut Of Point dan didapat hasil 13,5. Baik dikatakan < 13,5 dan Buruk dikatakan > 13,5.

Pengolahan data yang diperoleh dari hasil penelitian ini diolah secara manual dengan mengelompokkan hasil wawancara dan observasi kemudian dilakukan penghitungan skor dan dianalisis menggunakan uji statistik melalui sistem komuterisasi dengan beberapa tahap yaitu, editing, coding, processing, cleaning (Notoatmodjo, 2010). Analisa bivariat dalam penelitian ini yaitu untuk mengetahui hubungan pola asuh orang tua dengan perilaku jajan anak usia remaja di SD GMIM Sendangan Sonder. Peneliti menggunakan uji statistic Pearson ChiSquare dengan tingkat kemaknaan 95\% ( $\alpha$ $=0,05)$. 
HASIL dan PEMBAHASAN

1. Karakteristik Responden

Tabel 1. Distribusi Sampel Berdasarkan Umur

\begin{tabular}{ccc}
\hline Umur & $\mathrm{n}$ & $\%$ \\
\hline$<10$ & 40 & 62.5 \\
$>10$ & 24 & 37.5 \\
\hline Total & 64 & 100.0 \\
\hline \multicolumn{2}{l}{ Sumber: } & Data
\end{tabular}

Berdasarkan hasil menunjukan bahwa umur terbanyak berada pada kelompok umur < 10 Tahun yakni sebanyak 40 responden $62.5 \%$ dan responden umur $>10$ sebanyak 24 atau sebesar $37.5 \%$. Hasil ini sejalan dengan penelitian yang dilakukan Cholifatur, 2015 tentang hubungan antara tingkat pengetahuan dan perilaku anak sekolah dasar mengenai pemilihan makanan jajanan dengan status gizi di SD Negeri Kudu 02 Kecamatan Baki Kabupaten Sukoharjo didapatkan hasil umur 10 tahun yaitu sebanyak 43,9\% lebih banyak memilih jajan, sedangkan paling sedikit yaitu responden dengan umur 12 tahun sebanyak 9,8\%. Didapatkan golongan umur anak sekolah membutuhkan banyak perhatian baik dari keluarga, lingkungan dan teman-teman di sekitarnya. Anak juga memiliki aktivitas di luar rumah sehingga sering melupakan waktu dan sudah lebih aktif memilih makanan yang disukai (Cholifatur, 2015).

Tabel 2. Distribusi Sampel Berdasarkan Jenis Kelamin

\begin{tabular}{lcl}
\hline Jenis Kelamin & $\mathrm{n}$ & $\%$ \\
\hline Perempuan & 42 & 65.6 \\
Laki-laki & 22 & 34.4 \\
\hline Total & 65 & 100.0 \\
\hline
\end{tabular}

Sumber: Data Primer, 2019

Berdasarkan tabel 2 menunjukan bahwa jenis kelamin terbanyak adalah perempuan yakni sebanyak 42 responden atau sebesar $65.6 \%$ dan responden laki - laki sebanyak 22 responden atau sebesar 34.4\%. Sikap kemandirian pada anak usia sekolah dipengaruhi juga oleh jenis kelamin anak tersebut, anak laki-laki membutuhkan perhatian lebih banyak dibandingkan anak perempuan maka anak perempuan lebih terlatih untuk mandiri. Anak perempuan juga lebih mudah untuk berinteraksi dengan lingkungan baru atau teman baru (Cholifatur, 2015). Pola asuh orang tua juga dapat mempengaruhi perilaku anak perempuan dan laki-laki. Anak perempuan cenderung lebih patuh dibandingkan anak laki-laki, sehingga dalam hal ini anak perempuan lebih menyukai pemilihan jajan sesuai keinginannya dan lebih hati - hati dalam memilih jenis jajanan yang sehat atau lebih bersih.

\section{Analisa Univariat}

Tabel 3. Distribusi Sampel Berdasarkan Pola Asuh Orang Tua

\begin{tabular}{ccc}
\hline Pola asuh & $\mathrm{n}$ & $\%$ \\
\hline Permisif & 13 & 20.3 \\
Otoriter & 21 & 32.8 \\
Demokratis & 30 & 46.9 \\
\hline Total & 65 & 100.0 \\
\hline
\end{tabular}

Sumber: Data Primer, 2019

Berdasarkan tabel 3 menunjukan bahwa mayoritas responden mempunyai pola asuh masuk dalam kategori demokratis yakni sebanyak 30 responden atau sebesar $46.9 \%$, pola asuh otoriter sebanyak 21 responden dan sebanyak 13 pola asuh permisif atau sebesar $20.3 \%$. Penelitian ini sejalan yang dilakukan risqa, 2018 tentang hubungan pola asuh orang tua degan kemandirian anak usia prasekolah di TK Negeri Pembina Manado hasil penelitian atas menunjukkan bahwa sebagian besar sampel mendapat pola asuh demokratis yaitu sebanyak 42 orang $(72,4 \%)$.

Pola asuh demokratis mencerminkan sikap orangtua yang keras dan cenderung bertindak netral terhadap anak. Hal ini 
ditandai dengan bimbingan orang tua terhadap anak untuk patuh kepada semua perintah dan keinginan orangtua, kontrol yang sangat ketat terhadap tingkah laku anak, anak kurang mendapatkan kepercayaan dari orangtua, anak sering dihukum, apabila anak berhasil atau berprestasi anak jarang diberikan pujian dan hadiah. Pola asuh otoriter sebenarnya mencerminkan ketidakdewasaan orangtua dalam merawat anak tanpa mempertimbangkan hak-hak yang melekat pada anak. Akibatnya, anak semakin tertekan dan tidak leluasa menentukan masa depannya sendiri (Wicaksono \& Nurhayati, 2014). Bentuk pola asuh orang tua terhadap anak merupakan interaksi antara anak dan orang tua selama mengadakan kegiatan pengasuhan, mendidik, membimbing dan mendisiplin serta melindungi anak untuk mencapai kedewasaan sesuai dengan norma-norma yang berlaku di masyarakat. Pengaruh keluarga dalam pembentukan dan perkembangan kepribadian anak sangat besar karena eluarga merupakan kelompok sosial yang pertama dimana anak dapat berinteraksi, tempat anak belajar dan menyatakan dirinya sebagai makhluk sosial.

Tabel 4. Distribusi sampel berdasarkan Tipe Perilaku Jajan Anak Usia Sekolah

\begin{tabular}{lcl}
\hline Perilaku Jajan & $\mathrm{n}$ & $\%$ \\
\hline Baik & 44 & 68.8 \\
Buruk & 20 & 31.3 \\
\hline Total & 65 & 100.0 \\
\hline
\end{tabular}

Sumber: Data Primer, 2019

Hasil penelitian ini menunjukan bahwa sebagian besar responden perilaku jajan yang baik yakni sebanyak 44 responden atau sebesar $68.8 \%$ dan responden yang berperilaku buruk yakni sebanyak 20 atau sebesar 31. Hasil penelitian ini sejalan dengan Sitoresmi, 2014 tentang Hubungan pola asuh orang tua dengan perilaku jajan anak sekolah dasar di SD N. Lebak Grabag Magelang dengan populasi sebanyak 36 responden dan didapatkan hasil sebanyak 20 anak
(55.6) masuk dalam kategori perilaku jajan yang baik. Perilaku jajan anak yang baik dipengaruhi oleh faktor lingkungan sebab anak belum mampu membedahkan jajanan yang baik dengan yang tidak. Faktor lingkungan yang sangat berpengaruh terhadap perilaku jajan anak adalah peran orang tua. Orang tua harus menjadi salah satu sumber informasi yang mampu mengarahkan anak dalam perilaku jajan. Terbentuknya perilaku juga dipengaruhi oleh lingkungan, salah satunya adalah dukungan sosial Dalam hal ini dukungan yang paling berpengaruh selain keluarga adalah sekolah, di samping itu juga dapat disebabkan oleh pengaruh teman sebaya karena teman sebaya merupakan faktor sosial yang juga mampu mempengaruhi pemilihan makanan jajanan. Meniru kebiasaan teman sebaya mempengaruhi anak dalam mengambil keputusan terkait pemilihan jajanan (Ida, 2015).

\section{Analisa Bivariat}

Tabel 5. Hubungan Pola Asuh Orang Tua dengan Perilaku Jajan Anak Usia Sekolah (9-12 tahun) di SD GMIM Sendangan Sonder

\begin{tabular}{cccccccc}
\hline & \multicolumn{6}{c}{ Perilaku Jajan } & \multirow{2}{*}{$\mathrm{p}$} \\
\cline { 2 - 6 } Pola Asuh & \multicolumn{2}{c}{ Baik } & \multicolumn{2}{c}{ Buruk } & \multicolumn{2}{c}{ Total } & \\
\cline { 2 - 7 } & $\mathrm{n}$ & $\%$ & $\mathrm{n}$ & $\%$ & $\mathrm{n}$ & $\%$ & \\
\hline Permisif & 11 & 17.2 & 2 & 3.1 & 13 & 20.3 & \\
Demokratis & 9 & 14.1 & 12 & 18.8 & 21 & 32.8 & \multirow{2}{*}{0,007} \\
Otoriter & 24 & 37.5 & 6 & 9.4 & 30 & 46.9 & \\
\hline Total & 44 & 68.8 & 20 & 31.3 & 64 & 100 & \\
\hline Sumber. & Data & Primer, 2019 & &
\end{tabular}

Sumber: Data Primer, 2019

Berdasarkan hasil tabulasi silang menunjukan bahwa sebanyak 13 responden (20.3\%) yang mempunyai pola asuh yang permisif, terdapat 11 responden $(17.2 \%)$ yang perilaku jajan baik, terdapat 2 responden $(3.1 \%)$ yang perilaku jajan yang buruk. Terdapat sebanyak 21 responden $(32.8 \%)$ yang mempunyai pola asuh yang otoriter, terdapat 9 responden $(14.1 \%)$ yang perilaku jajan yang baik dan terdapat 12 responden $(18.8 \%)$ yang perilaku jajan yang buruk. Sebanyak 30 responden $(46.9 \%)$ yang mempunyai pola asuh yang 
demokratis, terdapat 24 responden $(37.5 \%)$ yang perilaku jajan baik, terdapat 6 responden $(9.4 \%)$ yang perilaku jajan yang buruk. Hasil analisis dengan menggunakan uji Chi-Square memperoleh nilai signifikan $=0.007$ atau lebih kecil dari nilai $\alpha 0.05$ maka dengan demikian dapat disimpulkan bahwa terdapat hubungan Pola Asuh Orang Tua dengan Perilaku Jajan di sekolah Usia 9-12 Tahun di SD GMIM Sendangan Sonder. Penelitian ini sejalan dengan riska, 2018 tentang hubungan pola asuh orang tua degan kemandirian anak usia prasekolah di TK Negeri Pembina manadohasil penelitian menggambarkan bahwa sebagian besar sampel mendapatkan pola asuh demokratis yaitu sebanyak 42 sampel $(72,4)$. Pola pemberian makan anak perlu dilakukan secara tepat karena kondisi anak berbeda dengan orang dewasa. Anak anak merupakan sosok manusia yang sedang mengalami perubahan dan perkembangan yang paling pesat dalam kehidupanya, yaitu perkembangan kematangan system pencernanan, kematangan organ-organ tubuh, otak, dan jiwa. Hal yang perlu diperhatikan tidak hanya menyangkut pemenuhan jumlah gizi yang tepat, tetapi juga bentuk fisik (tekstur) makanan dan cara pemberianya (Widodo, 2009).

Anak tidak pernah diberikan hukuman ketika melanggar peraturan yang ditetapkan orangtua. Sebab orangtua dengan pola asuh permisif menganggap anak mampu berpikir sendiri dan ia sendirilah yang merasakan akibatnya. Selain itu, ketidakacuhan orangtua mengembangkan emosi yang stabil pada anak. Anak akan bersifat mementingkan diri sendiri dan kurang menghargai orang lain (Wicaksono \& Nurhayati, 2014). Teman sebaya bisa menjadi faktor utama yang membuat anak yang telah diberi pola asuh demokrstis ini masih belum mandiri karena teman sebaya bisa sering membantu anak melakukan sesuatu yang seharusnya dilakukan oleh anak sendiri tanpa bantuan namun sering dibantu oleh teman sehingga membuat rasa percaya diri anak menjadi kurang dan anak akan merasa selalu membutuhkan orang lain yaitu temannya saat melakukan sesuatu. Kemandirian anak dapat dicapai jika pola pengasuhan orang tua terhadap anak tepat . Pola asuh orang tua yang tepat adalah pola asuh demokratis, karena pada pola pengasuhan demokratis orang tua lebih berfikir rasional dan memberikan anak kesempatan melakukan tugas perkembangannya.

\section{SIMPULAN}

Terdapat hubungan signifikan Pola Asuh Orang Tua dengan Perilaku Jajan di sekolah Usia 9-12 Tahun di SD GMIM Sendangan Sonder. Mayoritas responden memiliki pola asuh demokratis, mayoritas responden menunjukkan perilaku jajan yang baik.

\section{DAFTAR PUSTAKA}

Badan Pengawas Obat dan Makanan Republik Indonesia (BPOM RI). (2010). Uji Pangan Jajanan Sekolah. http://www.pom.go.id/new/index.ph $\mathrm{p} /$ view/berita.

Cholifatur, 2015 tentang hubungan antara tingkat pengetahuan dan perilaku anak sekolah dasar mengenai pemilihan makanan jajanan dengan status gizi di SD Negeri Kudu 02 Kecamatan Baki Kabupaten Sukoharjo, Jurnal

Devi, C. (2012). Hubungan Pola Asuh Orangtua dengan Kecerdasan Sosial pada Siswa Kelas VI SD Jatimulyo. Skripsi Fakultas Psikologi Universitas Islam Negeri (UIN) Maulana Malik Ibrahim Malang

Gunarsa. Singgih D. (2008). Psikologi Anak: Psikologi Perkembangan Anak dan Remaja. Jakarta: PT BPK Gunung Mulia.

Ida, 2015. Niat dan Perilaku Pemilihan Jajanan Anak Sekolah yang 
Mendapat Pendidikan Gizi Metode Ceramah dan TGT, Jurnal

Mukhammad, A. F. (2016). Hubungan antara Pengetahuan dan Sikap dengan Perilaku Konsumsi Jajanan Sehat di MI Sulaimaniyah Mojoagung Jombang. Skripsi, Univeritas Airlangga. Fakultas Kesehatan Masyarakat. Program Studi Kesehatan Masyarakat. Surabaya.

Notoadmodjo S. (2010). Metodologi penelitian kesehatan. Jakarta : Rineka cipta.

Oemar, R \& Novita, A. (2015). Pola asuh dalam kesehatan anak pada ibu buruh pabrik. Jurnal Kesehatan Masyarakat, 11(1), 112-124.

Safriana. (2012). Perilaku Memilih Jajanan pada Siswa Sekolah Dasar di SDN Garot Kecamatan Darul Imarah Kabupaten Aceh Besar. (Skripsi). Universitas Indonesia. Depok. http://lib.ui.ac.id/file?file=digital/203 14062-S_Safriana.pdf

Singgih D, Gunarso dan Yulia Singgih D Gunarso. 2004. Psikologi Praktis: Anak, Remaja dan Keluarga. Jakarta: Gunung Mulia.

Sitoresmi, 2014. Hubungan Pola Asuh Orang Tua Dengan Perilaku Jajan Anak Sekolah Dasar Usia 10-12 Tahun di SD Negeri Lebak Grabag Magelang, Jurnal.

Wicaksono, R. C. \& Nurhayati, F. Perbandingan Antara Pola Asuh Otoriter dengan Permisif Terhadap Status Gizi Siswa. ejournal unesa 2, 631-634 (2014).

WHO (2013). Children and adolescence. Geneva.

Widodo R, 2009. Pemberian Makanan, Suplemen, dan Obat Pada Anak. Jakarta: EGC. 